\title{
Discussion of influencing factors on filtration performances of PTFE membrane filters
}

\author{
Ning Mao ${ }^{1, \text { a }}$, Jingxian Liu ${ }^{1, b}$, Deqiang Chang ${ }^{1, \mathrm{c}}$ and Xi Sun ${ }^{1, \mathrm{~d}}$ \\ ${ }^{1}$ College of Resources and Civil Engineering, Northeastern University, \\ Shenyang,110004,China \\ ${ }^{a}$ maoning@mail.neu.edu.cn, ${ }^{b}$ liujingxian@mail.neu.edu.cn, \\ c changdeqiang@mail.neu.edu.cn, ${ }^{d}$ sunxi45@126.com
}

\begin{abstract}
The effects of many factors such as the properties of membrane and substrate, the lamination conditions on filtration performances of PTFE membrane filter have been experimentally researched in the paper. It is found that both the virgin pressure drop and residual pressure drop of membrane filters decrease with membrane pore size, and increase with membrane thickness and bonding strength. Similarly, the filtration cycle time of membrane filters increases with membrane pore size, and decreases with membrane thickness and bonding strength.

Keywords: membrane filter, substrate, pore size, membrane thickness, lamination condition.
\end{abstract}

\section{Introduction}

Filtration performances of a PTFE laminated membrane filter media could be affected by many factors such as the properties of membrane and substrate, the lamination conditions. In this paper, we will experimentally discuss on it from four aspects: a Effect of substrate fabric on filtration performance; b Effect of membrane pore size on filtration performance; c Effect of membrane thickness on filtration performance; d Effect of lamination condition on filtration performance. ${ }^{[1-5]}$

Therefore, the filtration performances of membrane filters can be summarized and concluded through the above research as to direct the select, design and evaluation on membrane filter in practice.

\section{Experimental}

Experimental setup. The schematic diagram of the experimental setup is shown in Fig.1. The dust laden gas is introduced into the top of the vertical duct, and the dust in the gas is collected on the test filter installed at the inlet of the horizontal 
duct. The filtration-regeneration cycle is controlled by either a prescribed filter pressure or time interval, and the cycle is repeated at a given filtration velocity.

Experimental procedure. In order to characterize the filtration performances of a seasoned filter, we run a pre-test at first. The procedure is as follows:

Step 1: Virgin performance test period: 30 filtration-cleaning cycles with a prescribed cleaning pressure drop (1000 Pa).

Step 2: Aging period: 5000 cycles with filter cleaning at a given interval of $5 \mathrm{~s}$

Step 3: Stabilizing period: 10 filtration-cleaning cycles with the prescribed cleaning pressure drop (1000 Pa).

Step 4: Performance test period: 30 filtration-cleaning cycles with the prescribed cleaning pressure drop (1000 Pa).

Two important parameters of residual pressure drop and filtration cycle time are taken as our indicators for the filter performance. The pressure drop after the filter cleaning is referred to as the residual pressure drop. The period between two consecutive filter cleanings is the filtration cycle time.

Experimental conditions. The test conditions are listed in Table 1. We also classify the tested filters into five groups and their properties are shown in Table 2.

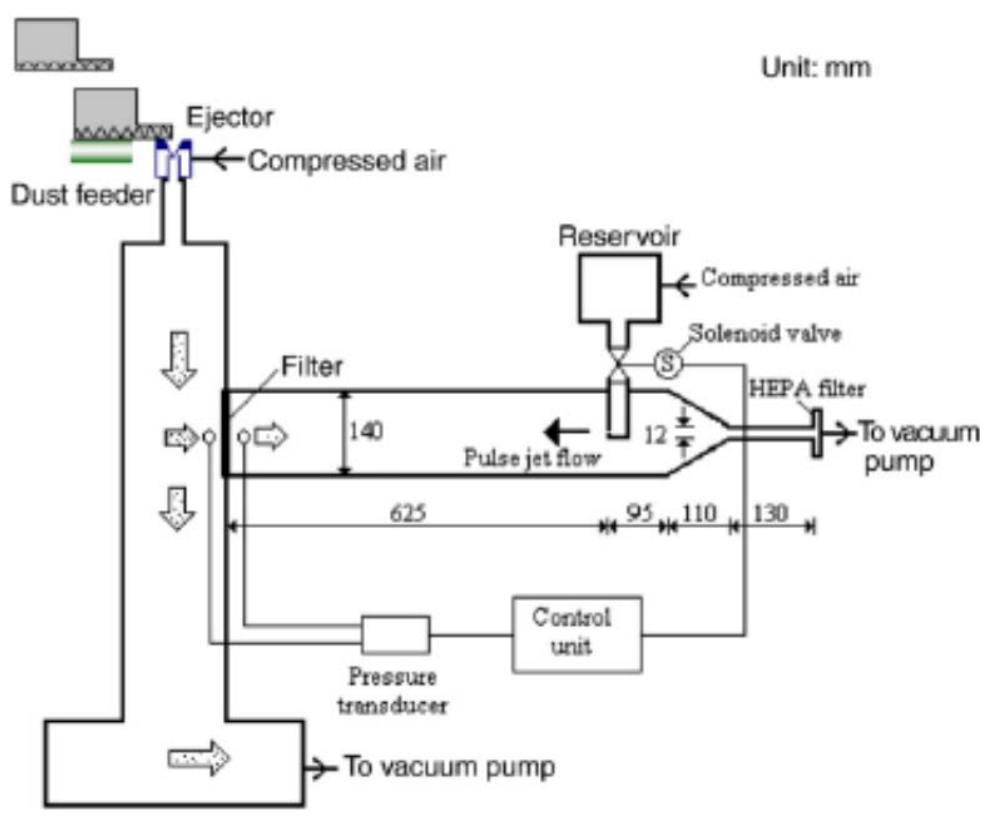

Fig. 1 Experimental setup for filter performance test 
Table 1 Testing conditions

\begin{tabular}{|c|c|c|c|c|c|}
\hline \multicolumn{3}{|c|}{ Dust } & \multirow[b]{2}{*}{$\begin{array}{c}\text { Filtration } \\
\text { velocity } \\
{[\mathrm{m} / \mathrm{min}]}\end{array}$} & \multirow[b]{2}{*}{$\begin{array}{c}\text { Pulse jet } \\
\text { pressure } \\
\text { [kPa-gauge] }\end{array}$} & \multirow{2}{*}{$\begin{array}{c}\text { Pressure } \\
\text { before } \\
\text { cleaning } \\
{[\mathrm{Pa}]}\end{array}$} \\
\hline Name & $\begin{array}{c}\text { Median } \\
\text { Diameter } \\
(\mu \mathrm{m})\end{array}$ & $\begin{array}{c}\text { Dust } \\
\text { concentration } \\
{\left[\mathrm{g} / \mathrm{m}^{3}\right]}\end{array}$ & & & \\
\hline $\begin{array}{c}\text { JIS No.10 } \\
\text { (fly ash) }\end{array}$ & 4.84 & \multirow{2}{*}{5} & \multirow{2}{*}{2} & \multirow{2}{*}{500} & \multirow{2}{*}{1000} \\
\hline $\begin{array}{c}\text { JIS No.11 } \\
\text { (loam) }\end{array}$ & 2.31 & & & & \\
\hline
\end{tabular}

Table 2 Properties of filter media

\begin{tabular}{|c|c|c|c|c|c|c|}
\hline \multirow{3}{*}{$\begin{array}{l}\text { Influencin } \\
\text { g factors }\end{array}$} & \multirow{3}{*}{ Filter } & \multirow{3}{*}{$\begin{array}{c}\text { Substrat } \\
\text { e }\end{array}$} & \multicolumn{3}{|c|}{ PTFE membrane } & \multirow{3}{*}{$\begin{array}{c}\text { Lamination } \\
\text { condition }\end{array}$} \\
\hline & & & \multirow[b]{2}{*}{$\begin{array}{l}\text { Thicknes } \\
\mathrm{s}(\mu \mathrm{m})\end{array}$} & \multicolumn{2}{|c|}{ Pore size $(\mu \mathrm{m})$} & \\
\hline & & & & $\begin{array}{l}\text { Median } \\
\text { diameter }\end{array}$ & $\begin{array}{c}\text { Maximum } \\
\text { diameter }\end{array}$ & \\
\hline \multirow{3}{*}{ Substrate } & A1 & Polyester & 8 & 0.9 & 2.2 & Standard \\
\hline & $\mathrm{A} 2$ & Acrylic & 8 & 0.9 & 2.2 & Standard \\
\hline & A3 & Conex & 8 & 0.9 & 2.2 & Standard \\
\hline \multirow{2}{*}{ Pore size } & B1 & Polyester & 20 & 3.0 & 5.9 & Standard \\
\hline & $\mathrm{B} 2$ & Polyester & 16 & 0.9 & 2.2 & Standard \\
\hline \multirow{3}{*}{$\begin{array}{l}\text { Membrane } \\
\text { thickness }\end{array}$} & $\mathrm{C} 1$ & Polyester & 8 & 0.9 & 2.2 & Standard \\
\hline & $\mathrm{C} 2$ & Polyester & 16 & 0.9 & 2.2 & Standard \\
\hline & C3 & Polyester & 24 & 0.9 & 2.2 & Standard \\
\hline \multirow{3}{*}{$\begin{array}{c}\text { Lamination } \\
\text { condition }\end{array}$} & D1 & Polyester & 8 & 0.9 & 2.2 & Strong \\
\hline & D2 & Polyester & 8 & 0.9 & 2.2 & Standard \\
\hline & D3 & Polyester & 8 & 0.9 & 2.2 & Weak \\
\hline
\end{tabular}

\section{Results and Discussions}

Effect of substrate fabric on filtration performance. In order to investigate if the filtration performance of membrane filters could be influenced by the substrate fabrics, we tested three filters A1, A2 and A3 which are polyester, acrylic and conex laminated with the same PTFE film. The results are shown in Figs.2and 3.

It can be seen that both the residual pressure drops and the filtration cycle times for A1, A2 and A3 are on the same level, which indicates that the filtration performances are mainly decided by the membrane rather than the substrate fabrics. It can then be deduced that the main purpose of the substrate fabric is to provide the physical strength for the membrane filters. 


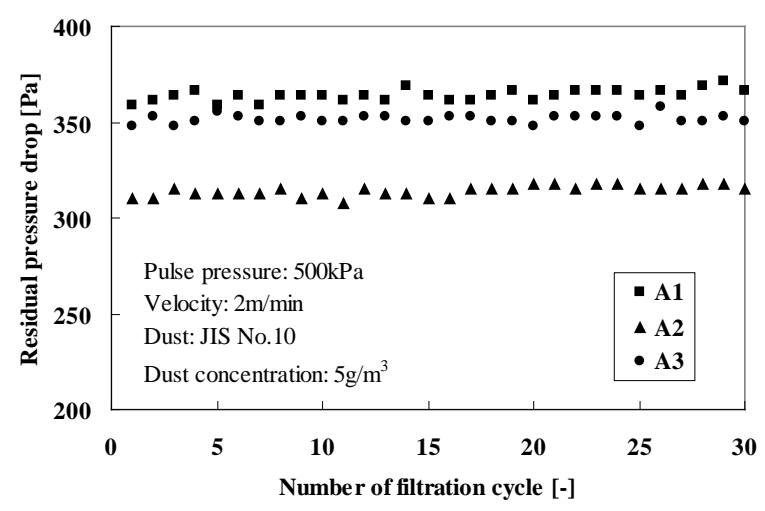

Fig. 2 Effect of substrate on residual pressure drop

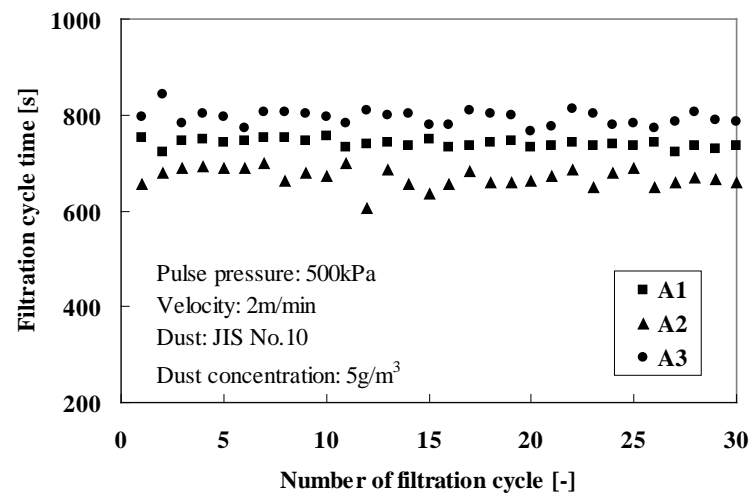

Fig. 3 Effect of substrate on filtration cycle time

Effect of membrane pore size on filtration performance. Filters B1 and B2 whose pore size of membrane are $3.1 \mu \mathrm{m}$ and $0.9 \mu \mathrm{m}$ respectively, are tested by the dusts of JIS No.10 and JIS No.11. The results are shown in Figs. 4 and 5. Since the pore size of B1 is larger than B2, the virgin pressure drop of B1 is lower than that of B2. The median diameter of JIS No.10 is $4.84 \mu \mathrm{m}$, which is larger than the pore size of both B1 and B2. Whereas the median diameter of JIS No.11 is $2.31 \mu \mathrm{m}$, which is lower than the pore size of B1 and larger than B2.

In Fig.4, B2 gives a lower residual pressure drop for JIS No. 11 test than JIS No.10 test, however, B1 gives a higher residual pressure drop for JIS No.11 test than JIS No.10 test. In Fig.10, for JIS No.10 test, B1 gives a higher filtration cycle time than that of B2, whereas B1 and B2 give nearly the same filtration cycle times for JIS No.11 test. It can be known that JIS No.11 has a bigger effect on B1 than B2 as its median diameter is lower than the pore size of B1. Therefore, we can conclude that the residual pressure drop increases and the filtration cycle time decreases more rapidly when the particle size is smaller than the membrane pore size. 


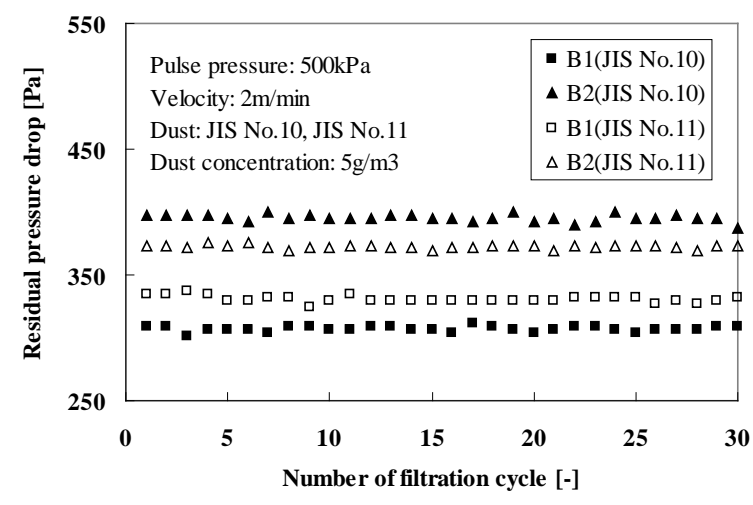

Fig. 4 Effect of pore size on residual pressure drop

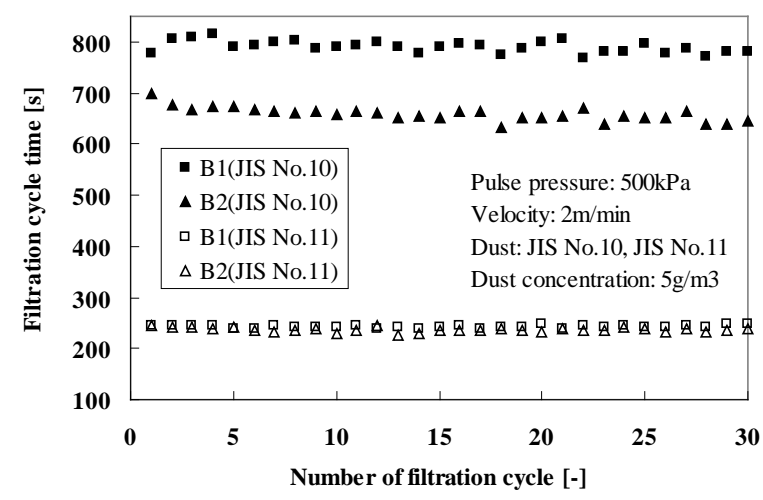

Fig.5 Effect of pore size on filtration cycle time

Effect of membrane thickness on filtration performance. Filters C1, C2 and C3 whose thickness of membrane are $8 \mu \mathrm{m}, 16 \mu \mathrm{m}$ and $24 \mu \mathrm{m}$ respectively, are tested by the dust of JIS No.10 and the results are shown in Figs. 6 and 7. It can be seen that the virgin filter pressure drop increases with the membrane thickness. In Fig.6, the residual pressure drop increases with the membrane thickness. In Fig. 7, the filtration cycle time decreases with the membrane thickness.

Effect of lamination condition on filtration performance. In the research, the non-woven fabrics are selected as substrate material on which PTFE film is laminated by an adhesive. The bonding strength between the substrate and the PTFE film is ranked as strong, standard and weak, which is corresponding to filters D1, D2 and D3 respectively. With the increase of the bonding strength, the virgin filter pressure drop also increases. The filters D1, D2 and D3 are tested and their results are shown in Figs.8 and 9. In Fig.8, the residual pressure drop increases with the bonding strength. In Fig.9, the filtration cycle time decreases with the bonding strength. 


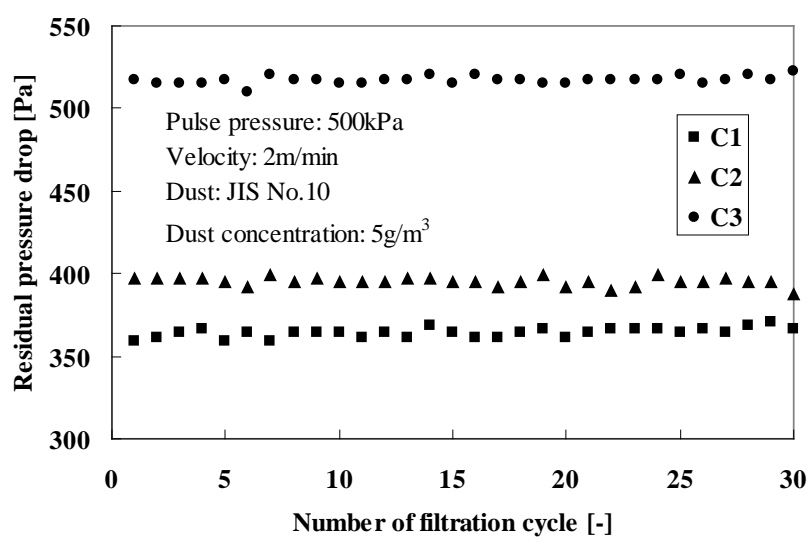

Fig. 6 Effect of membrane thickness on residual pressure drop

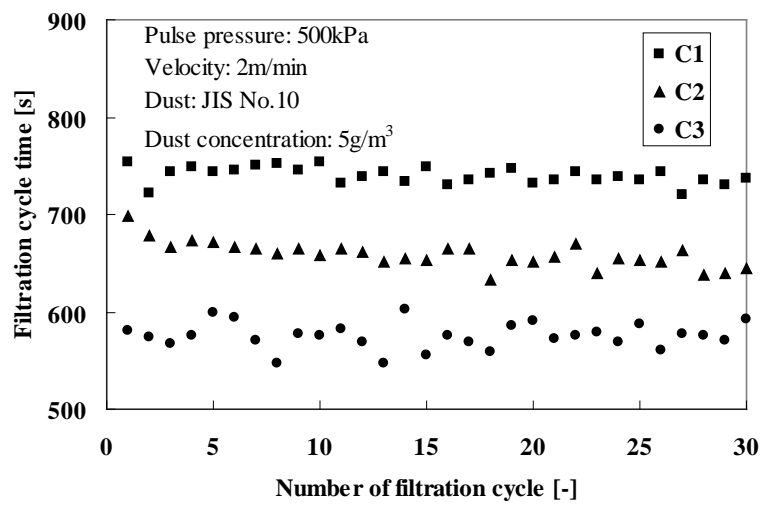

Fig. 7 Effect of membrane thickness on filtration cycle time

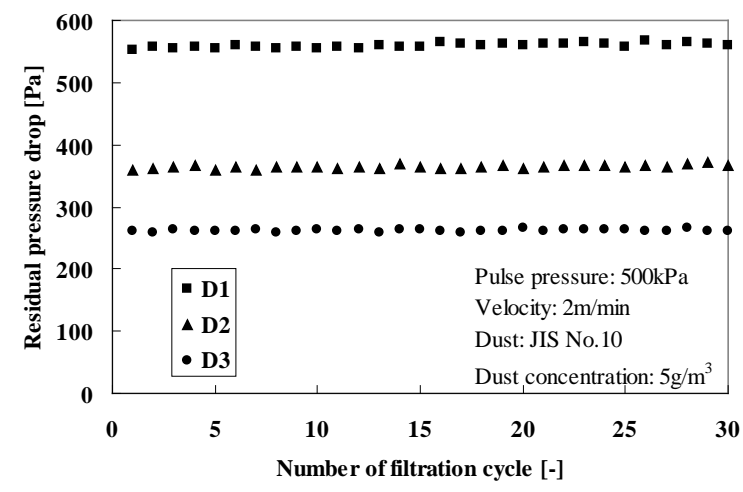

Fig. 8 Effect of lamination condition on residual pressure drop 


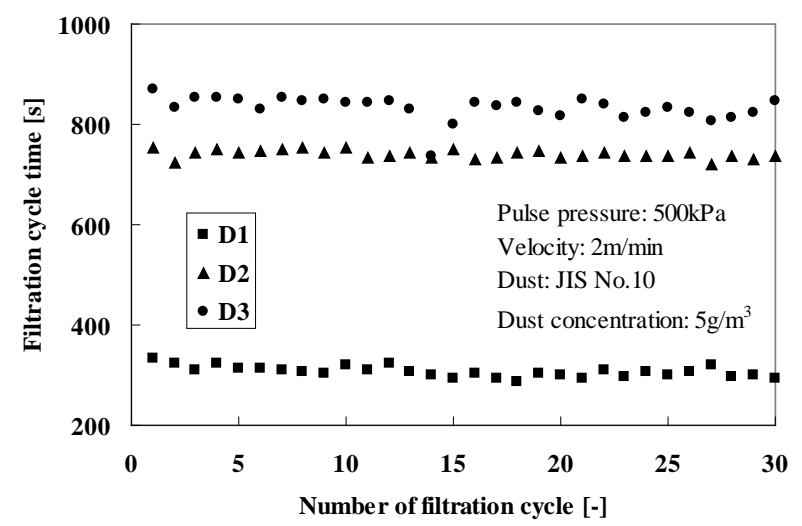

Fig. 9 Effect of lamination condition on filtration cycle time

\section{Conclusions}

1. Both the virgin pressure drop and residual pressure drop of membrane filters decrease with membrane pore size, and increase with membrane thickness and bonding strength. Similarly, the filtration cycle time of membrane filters increases with membrane pore size, and decreases with membrane thickness and bonding strength.

2. The residual pressure drop increases and filtration cycle time decreases faster when the particle size is lower than membrane pore size.

\section{Acknowledgement}

It is a project supported by the National Science and technology support program(2013BAC01B02) and the national high technology research and development program (863 Program) (2013AA065101).

\section{References}

[1] N. Mao, Y.P. Yao and C. Kanaoka, Comparison of filtration performances of cleanable fabric filters measured by VDI and JIS testing rigs, Advanced Powder Technology, 17(1), pp. 85-97(2006)

[2] N. Mao, Y. Otani, Y.P. Yao and C. Kanaoka, Modeling the filtration process with a flat-type fabric filter, Advanced Powder Technology, 17(3), pp. 237-256(2006) 
[3] N. Mao, Y.P. Yao, M. Hata, M. Wada, and C. Kanaoka, Comparison of filter cleaning performance between VDI and JIS testing rigs for cleanable fabric filter, Powder Technology, 180 （2008）, pp. 109-114

[4] C. Kanaoka, Y.P. Yao, Time Dependency of the Pressure Drop in a Flat Type Pulse Jet Fabric Filter, Kagaku Kogaku Ronbunshu, 29(2) 2003 267-271.

[5] J. Binnig, N. Mao, J. Meyer, M. Hata, G. Kasper and C. Kanaoka, Comparison of surface filter testing rigs according to VDI 3926 and JIS Z 8909-1, Filtration, 5(4), 253-258, 2005 